\title{
Simulation and Prediction of the Service Quality of China's Private Express Delivery and Its Influencing Factors Based on the System Dynamics Model
}

\author{
Daojun Zhong, School of Economics and Management, Zhoukou Normal University, Zhoukou, China*
}

\begin{abstract}
With the continuous development of China's private express delivery, how to improve the service quality and enable private express delivery company to gain a place in the fiercely competitive market has become a major issue faced by the manager. Therefore, the authors introduce the system dynamics method into the field of service quality evaluation to study the service quality of China's private express delivery. Through system dynamics modeling, they discover the sensitive factors that affect the service quality of China's private express delivery, namely logistics information technology, staff training, and organization and management capability. According to the results of the sensitivity analysis, policy experiments are conducted to obtain the optimal resource allocation plan. The results show that, if the new investment is regarded as $100 \%$, then the resource allocation plan corresponding to each subsystem is $37.2 \%$ of the new investment should be allocated to the logistics information technology subsystem.
\end{abstract}

\section{KEYWORDS}

Private Express Delivery, Service Quality, System Dynamics

\section{INTRODUCTION}

The express delivery industry first appeared in the United States in the 1960s, and China's express delivery industry gradually developed after the reform and opening up (Huang \& Liu, 2005). The "China Express Development Index Report" issued by the State Post Bureau of the People's Republic of China pointed out that in 2019, the average daily express delivery volume of express companies across the country exceeded 170 million, a year-on-year increase of $28.5 \%$. The national express delivery business volume exceeded 60 billion pieces, with a total of 63.52 billion pieces completed, a year-on-year increase of $25.3 \%$. The total business revenue of express delivery was 749.78 billion Yuan. It can be seen that the China's express delivery industry will continue to grow in the coming period ("China Express Development Index Report," 2020). According to the "Some Opinions on Promoting the Development of the Express Delivery Industry" issued by the Chinese State Council, by 2020, China's express delivery volume will reach 50 billion pieces, and the average annual business 
income will reach 800 billion Yuan. The market scale of the express delivery industry will reach the top in the world and there will be more outlets in the villages and township (China State Council, 2015).

After more than 30 years of development, the degree of marketization of China's express delivery industry has been continuously improved. Now the competitive landscape in China's express delivery industry mainly consists of three forces (Wu, 2009). The first one is China's state-owned express delivery company, whose representative is China Express Mail Service (EMS). The second one is the four giants of the international express delivery industry represented by DHL, UPS, TNT and FedEx. The third one is China's private express delivery companies represented by SF Express, STO Express, YTO Express and ZTO Express, etc. (Dean \& Page, 2011). Among them, after many years of development, China's private express delivery companies have already achieved significant competitive advantages, such as fast transportation, rapid response, low price, and good service. This made private express delivery deeply rooted in people's minds and become the first choice of many customers (Zhao \& Zhuang, 2011). Although China's private express delivery has tremendous advantages in terms of development speed and business scale, due to the lack of mandatory standards and low market access thresholds, there are still outstanding problems in the service quality of China's private express delivery, and these service quality issues are getting more and more attention from consumers. For example, express delivery companies illegally sell consumer personal information, arbitrarily sort, untimely delivery, unauthorized opening of parcels, and so on. This series of service problems has seriously damaged the legitimate rights and interests of consumers and also hindered the healthy development of China's private express delivery industry (Pan \& Jian, 2011). Therefore, the service quality of express delivery has aroused people's attention and become one of the research hotspots in academia.

The research on the service quality of express delivery was mainly focused on the field of logistics service quality in the early days and the representative one is the 7RS system established by Perreault and Russ (Perreault \& Russ, 1976). Mentzer, Gomes, and Krapfel have improved the dimensions of express service quality evaluation. They incorporated the safety, punctuality, and service process tracking of express delivery into the express service quality evaluation system, and constructed a new set of evaluation dimensions (Mentzer \& Gomes, 1989). Anderson, Crum and Jerman believed that the degree of improvement in service quality is affected by relevant management elements. They proposed five management dimensions of service quality: team collaboration, organizational structure, job performance, process control, and continuous improvement (Anderson, Crum, \& Jerman, 1996). Mentzer and Flint conducted research on key factors affecting distribution services, and in 2001 they integrated customer marketing and logistics distribution processes into the evaluation system of express service quality (Mentzer \& Flint, 2001). Rabinovich and Bailey evaluated the logistics service quality from seven aspects: distribution route, enterprise characteristics, warehouse location, and network system and so on (Rabinovich \& Bailey, 2004).

Although logistics and express delivery have many common features, the express delivery industry, as part of the logistics industry, is more refined and specialized, and has its own uniqueness. If blindly applying the method of evaluating the logistics service quality to the evaluation of express service quality, then the results will definitely be counterproductive. In addition, private express delivery as an important part of the express delivery industry, the service quality of it directly affects the development of the entire express delivery industry. Therefore it is necessary to focus on the service quality of private express delivery.

Research on the service quality of China's express delivery has mainly focused on the innovation of evaluation index systems and the improvement of evaluation models. Zhu and Miao revised and improved the SERVQUAL model in 2011. They added the security dimension to the original five dimensions (Zhu \& Miao, 2011). Li and Xie established the express service value chain model and established 14 key indicators from the aspects of goods packaging, corporate image, and after-sales service, and conducted an empirical study on the service quality of DHL (Li \& Xie, 2016). Zhuang and $\mathrm{Li}$ established an evaluation system from the six dimensions of safety, reliability, assurance, 
convenience, tangibility, and remedial measures, and adopted the CZIPA method to evaluate the service quality of express delivery companies (Zhuang \& Li, 2015). Yi, Hairui and Haichen combined the SERVQUAL model and the LSQ model to establish an evaluation system for China's express delivery service quality under the e-commerce environment and proposed a path to improve service quality (Dang \& Wagn, 2016).

From the perspective of research methods, among the existing research results of the service quality of private express delivery, the most commonly used method by scholars is the SERVQUAL model. Some scholars combined it with LSQ model, analytic hierarchy process, gray correlation analysis and other methods (De Giovanni, Gastaldon, \& Sottovia, 2019; Vakulenko, Hellström, \& Hjort, 2018). When using these methods to study the service quality of private express delivery, the independent variables included were relatively limited due to the constraints and restrictions of choosing independent variables. In addition, from the perspective of research angle, among the existing research results, the research on private express delivery service quality is mostly based on a single research angel, such as from the angle of government, business, consumers, or a combination of business and consumers (Kafle, Zou, \& Lin, 2017; Kim, Dekker, \& Heij, 2017; Olbert, ProtopappaSieke, \& Thonemann, 2016; Zenezini, Lagorio, Pinto, De Marco, \& Golini, 2018). These studies fragmented the relevance of various objects, lack of systematic thinking, and didn't treated the service quality of private express delivery as a complex system. This means that existing research results need to be further supplemented and improved.

Few scholars have applied the research method of system dynamics of the engineering field to the service quality evaluation. Forrester pioneered and applied the method of system dynamics to the field of enterprise management, and studied the activities of production operations and inventory control of enterprises. His research results laid the foundation for the application of system dynamics in the fields of logistics management and service quality management (Forrester, 1958, 1994). Therefore, we use systematic thinking to view the service quality of China's private express delivery, and boldly introduce the system dynamics method into the field of service quality evaluation to study the service quality of China's private express delivery. First of all, combined with the related knowledge of system theory, quantitative modeling was carried out to construct a system dynamics model of private express delivery service quality. Subsequently, through the policy simulation experiment of the system dynamics model, the countermeasures to promote the improvement of the China's private express delivery service quality are proposed. By clarifying the factors affecting the service quality of private express delivery and evaluating the service quality will help private express delivery companies recognize their own defects. At the same time, targeted rectification of defects can enable consumers to enjoy a higher level of service.

\section{RESEARCH METHODOLOGY}

When building a system dynamics model, certain steps and processes need to be followed. In general, the process of system dynamics modeling can be divided into five steps: system analysis, qualitative modeling, quantitative modeling, model verification and testing, model simulation and experiment (Angerhofer \& Angelides, 2000).

The first step in system dynamics modeling is system analysis, which determines the system boundary according to the characteristics of the research object and grasps the basic composition of the system. The second step: qualitative modeling, which is based on the results of the system analysis to determine the causal relationship between the various variables of the model, and then establish a causal chain and causal feedback loop. The third step: quantitative modeling, that is, establish the weight of each major variable, determine the system's level variables, flow rate variables, auxiliary variables and constants, and draw the system flow chart of the model. The fourth step: model validation and testing, that is, test and adjust the completed system dynamics model, and modify and improve the shortcomings. Step 5: Model simulation and experimentation, that is, the simulation and prediction of 
the development trend of the system, combined with the results of the sensitivity analysis to conduct policy experiments, so as to find solutions to the problem.

Figure 1. System dynamics modelling process

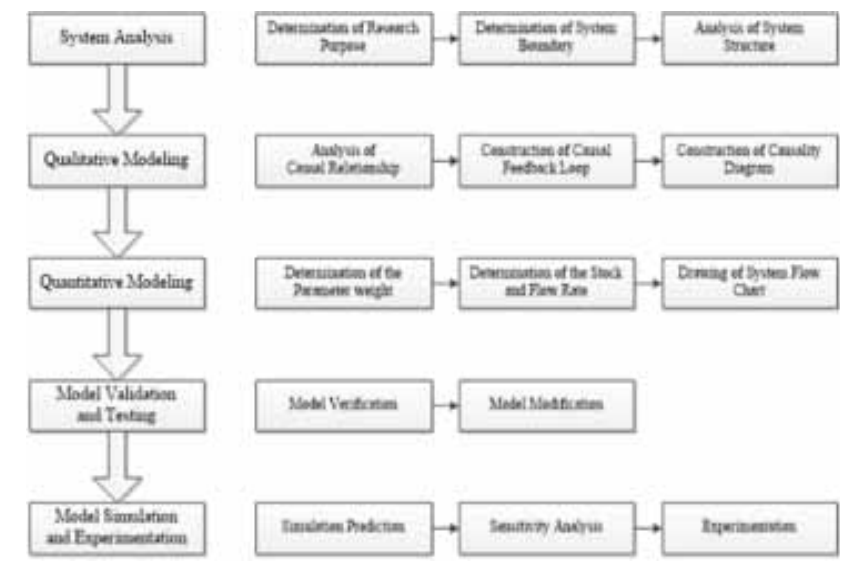

\subsection{System Dynamics Simulation Software}

Simulation software does not require users to master esoteric mathematical algorithms and mathematical equations, nor does it require users to write complex computer codes. It has the obvious characteristics of simplicity and ease of use (Abdel-Hamid, 1989). As far as the system dynamics simulation software is concerned, Modus, STELLA \& iThink, Vensim, and so on are currently the most widely used software for business activity management and corporate decision making. This study used the Vensim software, a visual system dynamics modeling tool based on the Windows environment, providing a powerful graphical editing interface with strong data sharing. Vensim software not only provides analysis tools such as reason tree, result tree and feedback loop, but also allows users to verify and judge the main variables in the model in advance (Luna-Reyes \& Andersen, 2003).

\subsection{System Thinking}

System dynamics considers all social systems, economic systems, and ecological environmental systems as complex systems. These complex systems all have non-linear, high-order, and multi-loop characteristics. Although human beings are inextricably linked to these complex systems, people's ability to control such complex systems is very limited. However, humans can change the internal structure and operating state of a complex system through some means and control strategies, so that the complex system can be controlled by human beings to a certain extent (Sterman, 2001). As far as the social-economic system is concerned, it combines the features of a self-organizing system with the characteristics of a man-made system. The non-linear relationship between the internal elements of the social-economic system determines the complexity of the system, and the entire system will also be affected by the external interaction forces and boosting forces. In the entire process of determining system boundaries, establishing causal feedback loops, drawing causality diagrams, and constructing quantitative models, system thinking must be followed. 


\subsection{Determination of the System Boundary}

The express service quality system belongs to the open system within the large socio-economic system. Open systems can exchange material, energy, and information between itself and the external environment, but the prerequisite for this exchange is to determine system boundary(Kao, Chen, $\mathrm{Wu}$, \& Yang, 2005). The determination of system boundaries determines the exogenous and endogenous variables of the system. Endogenous variables are variables determined by the internal feedback structure of the system dynamics model, while exogenous variables are variables determined by external factors of the system dynamics model. We regard endogenous variables as the main body of systematic research, and exogenous variables as environmental factors.

The main research object of this article is the service quality of private express, so the service quality of private express should be treated as the system center. Elements related to the private express delivery service quality, such as the level of logistics information technology, staff professionalism, and organizational management capability, can be considered endogenous variables of the system. Elements that are only indirectly related to the private express delivery service quality or that are not explicitly related can be considered as exogenous variables of the system.

\subsection{System Structure Analysis}

Through the analysis of the system structure, it is possible to clarify the relationship between the various elements within the subsystem and the mutual relationship between the subsystems. The system structure analysis includes three aspects: connotation analysis, internal structure and relationship analysis, and influencing factors analysis (Lin, 2016).

Connotation analysis: Through connotation analysis, the factors that affect the private express delivery service quality are summarized into three aspects of the logistics information technology level, the staff professionalism and the organization and management capability. Logistics information technology level is composed of order processing quality, payment system quality and customer service system quality. The staff professionalism include not only the quality of the employees "work in sorting, warehousing, transportation and distribution, but also the employees' ability to handle special situations and their service attitude when facing customers. Organization and management capability are mainly reflected in three aspects: resource utilization rate, assessment management system and store management level.

Analysis of the internal structure and relationship: the logistics information technology level, the staff professionalism and the organization and management capability jointly determine the service quality of private express delivery. These three influence and interact with each other, and will also be affected by the external environment of the system.

Analysis of influencing factors: After clarifying the connotation of the private express delivery service quality and the internal structure and relationship of the system, it is also necessary to conduct an analysis on the influencing factors of the private express delivery service quality and find out the relatively important factors. First of all, the level of logistics information technology is affected by three aspects: order processing, payment experience and customer service quality. Secondly, the staff professionalism is affected by three aspects: quality of operation activities, quality of staff service, emergency response capability. Finally, the organization and management capability are affected by three aspects: assessment system, resource utilization rate, and store management level.

\subsection{Construction of the Model}

According to the results of system structure analysis, with the help of causality diagrams, feedback loops and other forms, the system dynamics model of the service quality of China's private express delivery can be established.

There is a mutual influence between the logistics information technology level and the staff professionalism and the organization and management capability. In addition, various factors that affect the level of logistics information technology can ultimately be attributed to the factor of information 
technology investment. Various factors that affect the staff professionalism can ultimately be attributed to staff training investment. Various factors that affect the organization and management capability can ultimately be attributed to the organization and management investment. Business income is the most critical factor affecting the investment, because the business income of express delivery companies directly determines the amount of resources they can invest in the field of information technology, staff training and the organization and management. From the perspective of service quality, good service quality can improve customer satisfaction, thereby increasing the number of customers and increasing the business volume and business income. On the other hand, the increase in business income can in turn ensure the companies can invest more resources in the field of information technology, staff training and the organization and management. Finally, based on the causality of the logistics information technology level subsystem, staff professionalism subsystem and the organization and management capability subsystem, each variable is quantified so as to clarify the impact of various elements on the service quality of private express delivery.

The three subsystems of logistics information technology level, staff professionalism and the organization and management capability will directly affect the service quality of private express delivery, and indirectly affect the number of customers and business income. Therefore, by integrating the models of the three subsystems, and then removing the redundant elements, the entire system dynamics model of China's private express service quality can be obtained.

\section{RESULTS}

The system of private express delivery service quality includes the logistics information technology level subsystem, the staff professionalism subsystem and the organization and management capability subsystem. When constructing the system dynamics model of private express delivery service quality, a complete system dynamics model can be obtained by merging the system dynamics of all subsystems. The modeling results of each subsystem will be omitted here and the entire model will be given instead. The entire model is shown below.

\subsection{Simulation Prediction}

After the completion of the system dynamics modeling, the system dynamics model has passed the verification and test, and then the next important task is model simulation and trend prediction. Because a qualified system dynamics model not only reflects the overall and systematic characteristics of the research object, but also can predict the development trend of the research object in the future. Typical representatives of China's private express delivery mainly include SF Express, STO Express, ZTO Express, YTO Express and Yunda Express. After comprehensively considering factors such as the representativeness and the availability of the data, we decided to select the four private express delivery companies, STO Express, ZTO Express, YTO Express and Yunda Express, as the objects of empirical analysis.

\subsubsection{Simulation Prediction: Service Quality}

Running the system dynamics model, the service quality of the four express delivery companies, STO Express, YTO Express, ZTO Express and Yunda Express, during the period 2014-2019 can be obtained. Then change the initial time of the model to 2020, the final time to 2025, and run it again to obtain the service quality development trend during 2020 to 2025 . The simulation and prediction results of service quality are shown below.

In order to accurately interpret and analyze the results of simulation prediction, it is necessary to derive the key data of the simulation and prediction results. The simulation results of 2014-2019 and the prediction results of 2020-2025 are exported and organized into a table. The results are shown in the following table. 


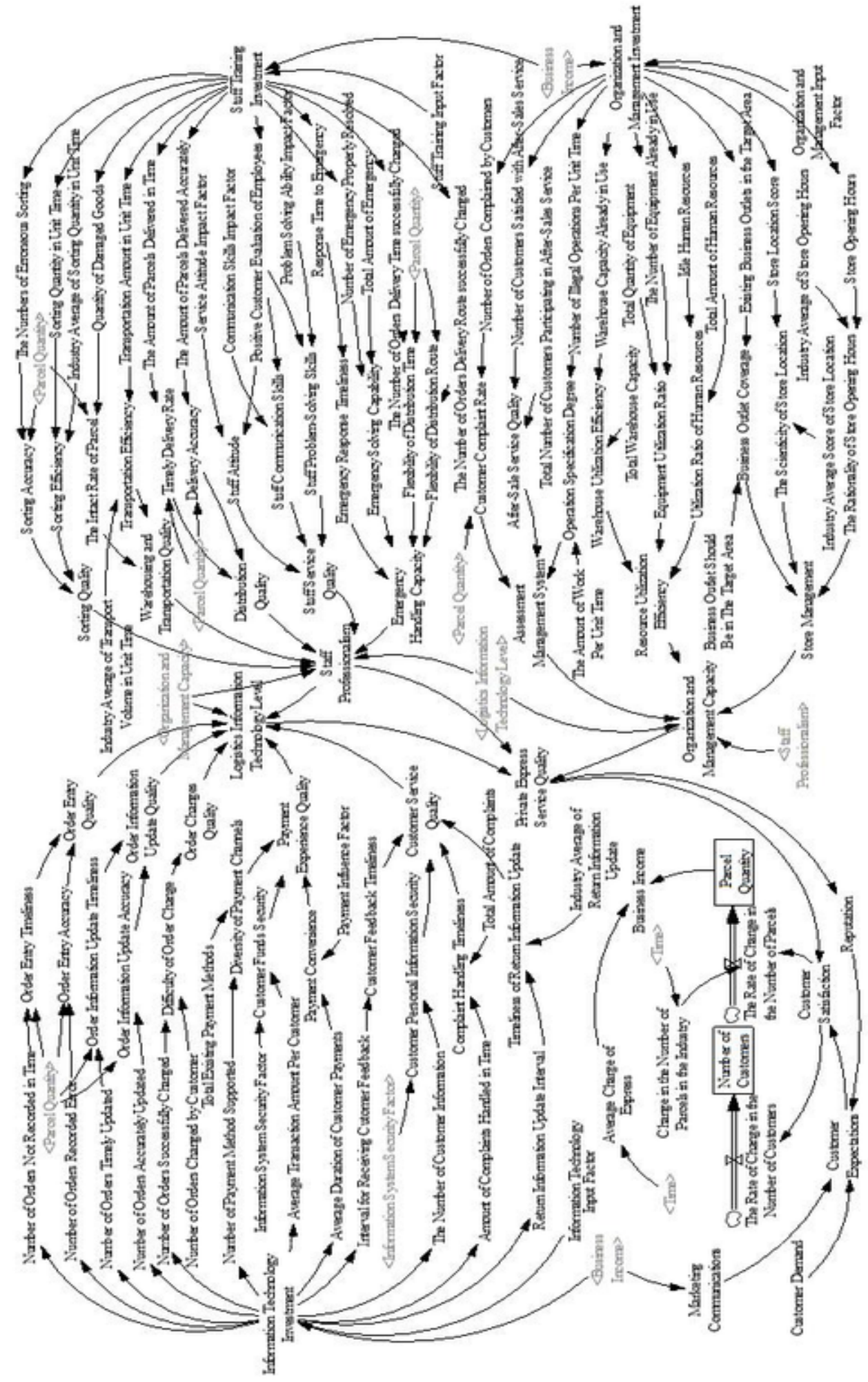


Figure 3. Simulation and prediction curve of service quality of the four express delivery companies

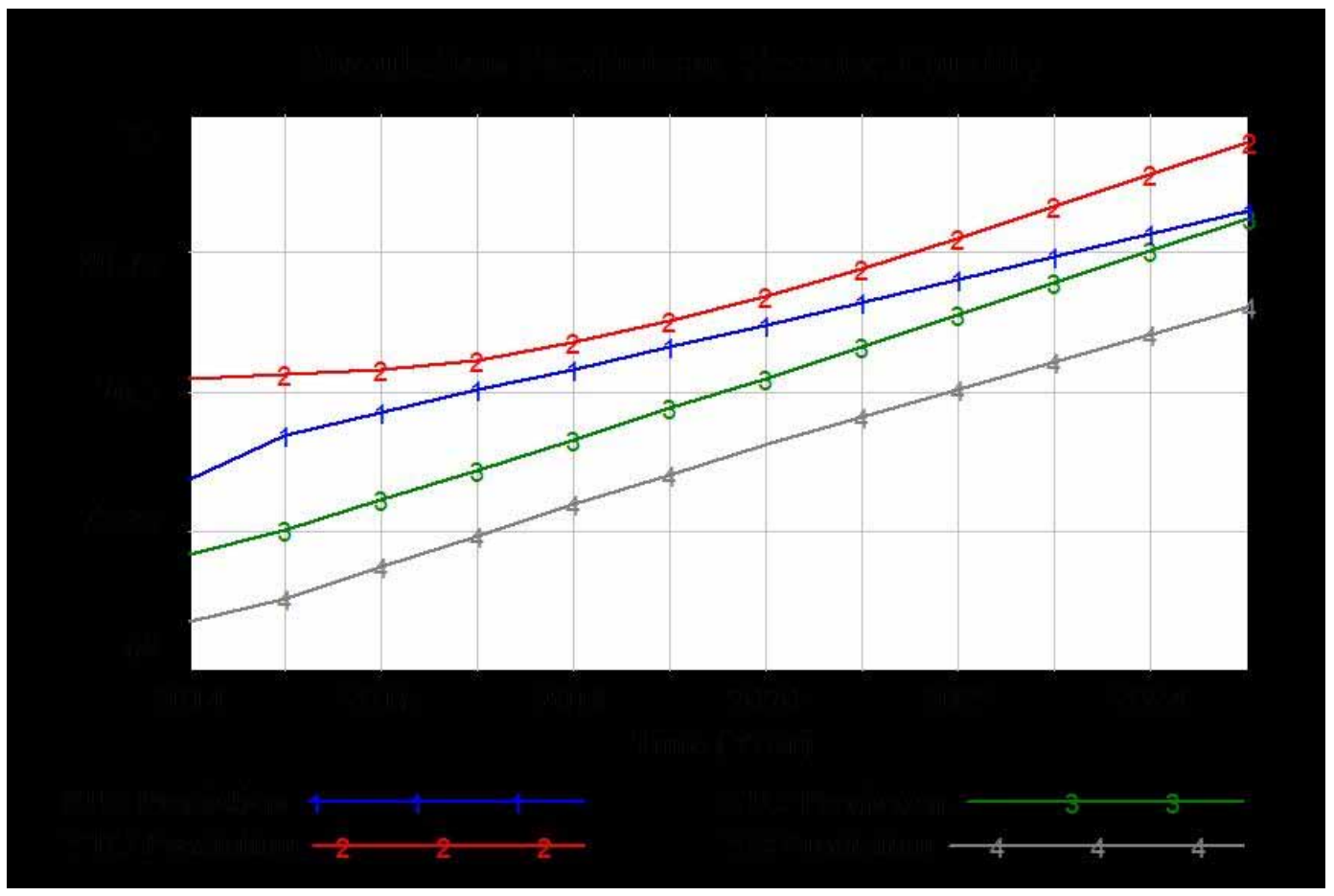

Table 1. Simulation and prediction results of service quality of the four express delivery companies

\begin{tabular}{|l|l|l|l|l|l|l|}
\hline & $\mathbf{2 0 1 4}$ & $\mathbf{2 0 1 5}$ & $\mathbf{2 0 1 6}$ & $\mathbf{2 0 1 7}$ & $\mathbf{2 0 1 8}$ & $\mathbf{2 0 1 9}$ \\
\hline STO & 73.83 & 75.14 & 75.89 & 76.56 & 77.22 & 77.88 \\
\hline ZTO & 71.54 & 72.32 & 73.20 & 74.12 & 75.05 & 75.99 \\
\hline YTO & 76.95 & 77.07 & 77.23 & 77.50 & 78.02 & 78.69 \\
\hline YD & 69.48 & 70.20 & 71.15 & 72.12 & 73.06 & 73.97 \\
\hline & 2020 & 2021 & 2022 & 2023 & 2024 & 2025 \\
\hline STO & 78.55 & 79.23 & 79.92 & 80.62 & 81.33 & 82.05 \\
\hline ZTO & 76.93 & 77.89 & 78.86 & 79.83 & 80.82 & 81.82 \\
\hline YTO & 79.46 & 80.30 & 81.19 & 82.13 & 83.12 & 84.14 \\
\hline YD & 74.86 & 75.73 & 76.58 & 77.42 & 78.26 & 79.10 \\
\hline
\end{tabular}

According to the figure and related data of the simulation prediction of service quality of four express delivery companies during 2014-2025, it can be seen that even during the period of 20142017, the growth rate of the YTO Express's service quality is not as good as the other three express delivery companies. But YTO Express's service quality has always been in the leading position among the four express delivery companies. The overall growth rate of STO Express's service quality is the slowest among the four express delivery companies. If it follows this trend, its service quality will soon be surpassed by ZTO Express. The service quality of the other two express delivery companies, 
namely ZTO Express and Yunda Express, still has a certain gap compared with YTO Express. But ZTO and Yunda always maintained a relatively fast growth rate, and ZTO Express has a slightly faster growth rate than Yunda Express. In general, the service quality of the four express delivery companies will continue to improve with the development of the company, and they all have shown a continuous upward trend. The ranking results of the four express companies from 2020 to 2025 in terms of service quality are as follows: YTO Express, STO Express, ZTO Express, and Yunda Express.

\subsubsection{Simulation Prediction: Parcel Quantity}

Setting the initial time and the final time of the model to 2020 and 2025 respectively, and then run the model to predict the future development trend of the parcel quantity of the four express delivery

Figure 4. Simulation prediction curve of parcel quantity of the four express delivery companies

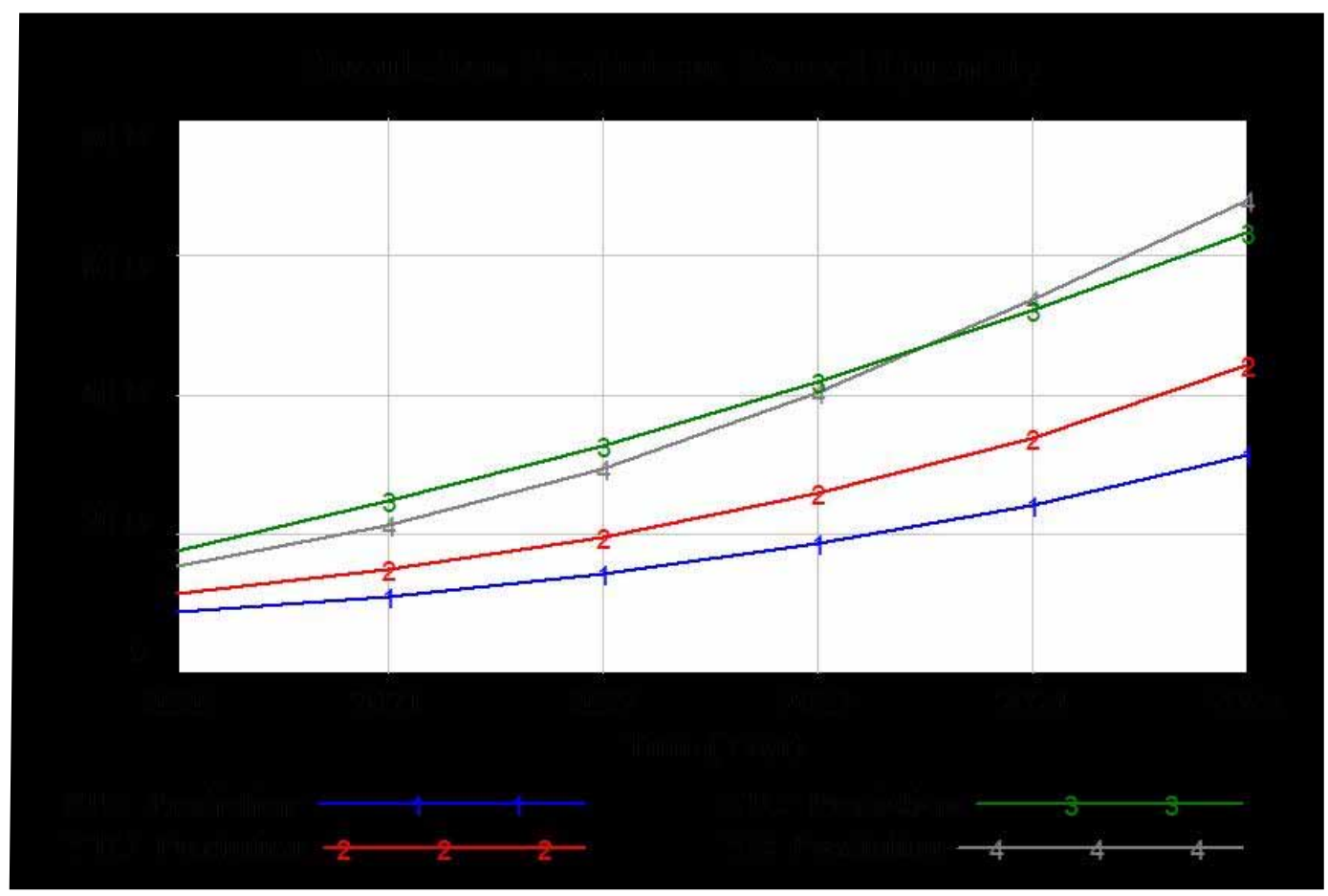

Table 2. Simulation prediction results of parcel quantity of the four express delivery companies

\begin{tabular}{|c|c|c|c|c|c|c|}
\hline \multicolumn{1}{|l|}{ Unit: Billion Yuan } \\
\hline & 2020 & 2021 & 2022 & 2023 & 2024 & 2025 \\
\hline STO & 8.646 & 11.167 & 14.440 & 18.689 & 24.206 & 31.37 \\
\hline ZTO & 17.550 & 24.87 & 32.8 & 42.13 & 52.02 & 63.43 \\
\hline YTO & 11.439 & 14.987 & 19.640 & 25.744 & 33.752 & 44.255 \\
\hline YD & 15.378 & 21.14 & 29.51 & 40.36 & 53.78 & 68.05 \\
\hline
\end{tabular}


Figure 5. Simulation prediction curve of business outlets of the four express delivery companies

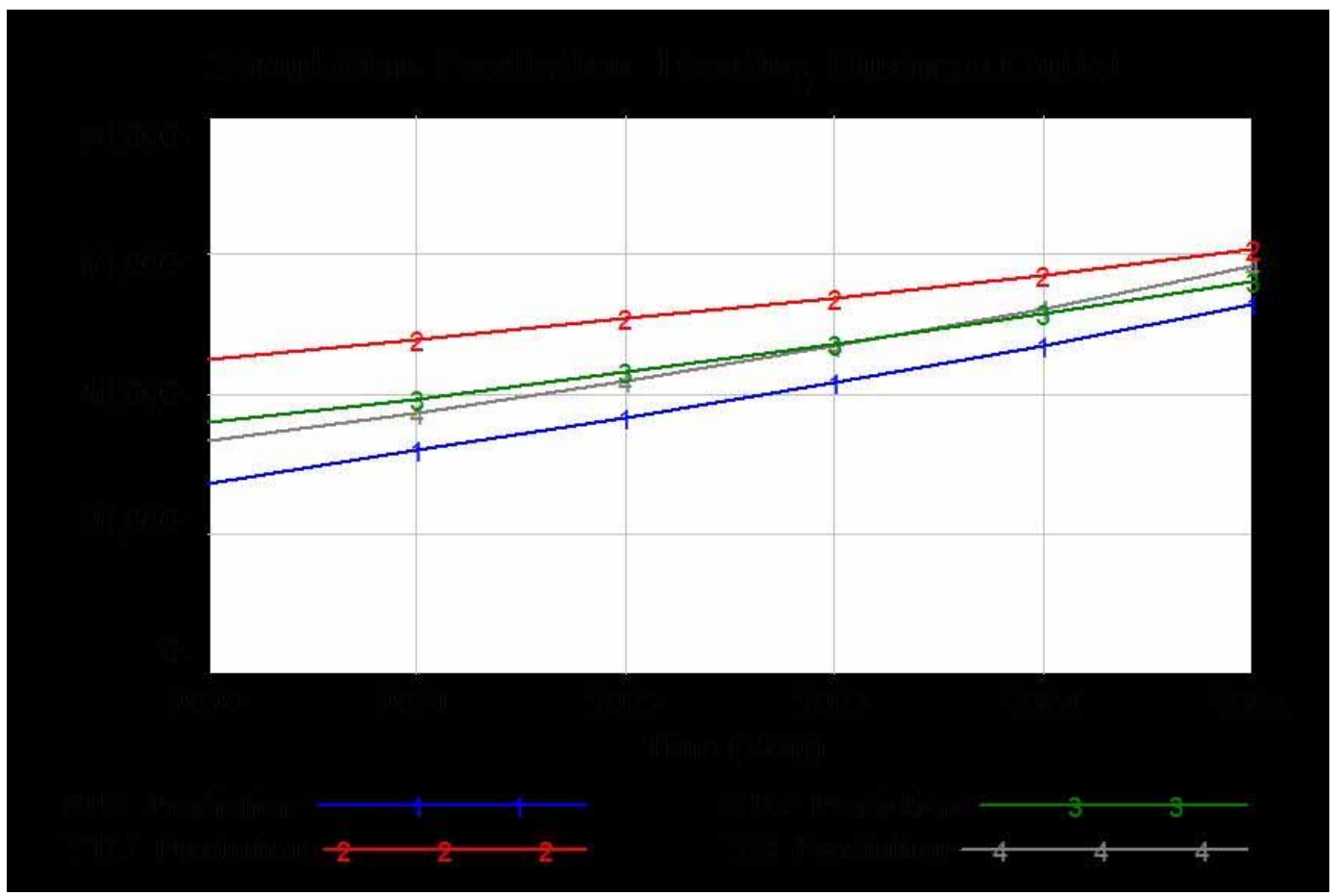

companies, STO Express, YTO Express, ZTO Express and Yunda Express. The prediction results of the parcel quantity from 2020 to 2025 are shown below.

Export and organize the prediction results for 2020-2025 into a table. The final results are shown in the following table.

According to the figure and related data of the simulation prediction of parcel quantity of the four express delivery companies during 2020-2025, Yunda Express's parcel quantity growth rate is the fastest among the four express delivery companies, with an average growth rate of $34.64 \%$. Before 2023, Yunda Express has been ranked second in the parcel quantity. From 2024, it will surpass ZTO Express and become the express delivery company with the largest parcel quantity. As far as STO Express and YTO Express are concerned, although their service quality is at the forefront among the four express delivery companies, the competitiveness in terms of parcel quantity, that is, market share, still has a clear gap compared with ZTO Express and Yunda Express. Although the parcel quantity of ZTO Express is not growing as fast as Yunda Express, the absolute amount of parcels is far greater than that of YTO Express and STO Express. In general, with the development of China's e-commerce and the continuous growth of the population, the parcel quantity of the four express delivery companies have shown a continuous growth trend. The forecast results of the parcel quantity of the four express delivery companies during 2020-2025 from large to small is as follows: ZTO Express, Yunda Express, YTO Express, and STO Express.

\subsubsection{Simulation Prediction: Business Outlets}

Setting the initial time and the final time of the model to 2020 and 2025 respectively, and then run the model to predict the future development trend of the business outlets of the four express delivery companies, STO Express, YTO Express, ZTO Express and Yunda Express. The prediction results of the business outlets from 2020 to 2025 are shown below. 
Export and organize the prediction results for 2020-2025 into a table. The final results are shown in the following table.

Table 3. Simulation prediction results of business outlets of the four express delivery companies

\begin{tabular}{|c|c|c|c|c|c|c|}
\hline & $\mathbf{2 0 2 0}$ & $\mathbf{2 0 2 1}$ & $\mathbf{2 0 2 2}$ & $\mathbf{2 0 2 3}$ & $\mathbf{2 0 2 4}$ & $\mathbf{2 0 2 5}$ \\
\hline STO & 27224 & 32090 & 36800 & 41710 & 47010 & 52810 \\
\hline ZTO & 36106 & 39474 & 43134 & 47109 & 51426 & 56116 \\
\hline YTO & 45093 & 47818 & 50742 & 53879 & 57246 & 60858 \\
\hline YD & 33339 & 37430 & 41930 & 46879 & 52321 & 58305 \\
\hline
\end{tabular}

According to the figure and relevant data of the simulation prediction of the business outlets of the four express delivery companies during 2020-2025, it can be seen that the number of business outlets of STO Express has grown the fastest. From 27,224 outlets in 2020 to 52,810 outlets in 2025, the growth rate is $93.98 \%$. Yunda Express will have 46,879 business outlets in 2023, and the ranking of business outlets will exceed ZTO Express and rise to the third place. The growth rate of YTO Express's business outlets is the slowest among the four express delivery companies, mainly because YTO Express already has a considerable number of business outlets, and its number of business outlets has always ranked first among the four companies. The number of business outlets of ZTO Express has been at the midstream level, and will increase from 36,106 in 2020 to 56,116 business outlets in 2025. In general, with the development of the express delivery industry, express delivery companies will pay more and more attention to the construction of business outlets, and the number of business outlets of the four express delivery enterprises will show a continuous growth trend. The forecast results of the number of business outlets of the four express delivery companies at the time point of 2025 are ranked from more to less: YTO Express, Yunda Express, ZTO Express, and STO Express.

\subsection{Sensitivity Analysis}

Another extremely important role of the system dynamics model is that policy experiments can be carried out by modifying certain specific parameters in the model. Before doing policy experiments, there is another necessary work to be completed, that is to conduct sensitivity analysis. Only after finding out the sensitive factors in the model through sensitivity analysis, the policy experiment can be successfully done. The system dynamics model of the private express delivery service quality contains three subsystems, and the impact of each subsystem should be taken into account. However, the variables in each subsystem are different, so it is necessary to select the same type of parameters in the three subsystems as the object of sensitivity analysis. After comprehensive consideration of comparability and feasibility, it is proposed to select the information technology input factor in the logistics information technology level subsystem, the staff training input factor in the staff

Table 4. Results of sensitivity analysis

\begin{tabular}{|c|c|c|c|c|c|c|}
\hline & $\mathbf{2 0 2 0}$ & $\mathbf{2 0 2 1}$ & $\mathbf{2 0 2 2}$ & $\mathbf{2 0 2 3}$ & $\mathbf{2 0 2 4}$ & $\mathbf{2 0 2 5}$ \\
\hline Sensitivity: Information Technology Input Factor & 0.426 & 0.423 & 0.420 & 0.417 & 0.415 & 0.412 \\
\hline Sensitivity: Organization and Management Input Factor & 0.236 & 0.234 & 0.232 & 0.230 & 0.229 & 0.227 \\
\hline Sensitivity: Staff Training Input Factor & 0.463 & 0.467 & 0.472 & 0.477 & 0.482 & 0.486 \\
\hline
\end{tabular}


professionalism subsystem, and the organization and management input factor in the organization and management capability subsystem as the parameter of sensitivity analysis.

Since the four express companies use the same model, it is sufficient to select one express company for sensitivity analysis. Here, STO Express is used as an example to perform sensitivity analysis, so the calculated service quality is the service quality of STO Express after adjusting each parameter.

In order to compare and analyze the sensitivity of the three parameters of information technology input factor, staff training input factor, organization and management input factor, it is necessary to set a unified parameter variation range. Assume that the value of each parameter is uniformly adjusted up by $10 \%$ on the basis of the original value. The specific idea of sensitivity analysis is: comparing the service quality before each parameter adjustment with the service quality after the parameter adjustment to obtain the percentage of service quality change, and then this value will be divided by the parameter change percentage to get the sensitivity of each parameter. The results of the sensitivity analysis of the three parameters are shown below.

The adjusted service quality of the three parameters of information technology input factor, organization and management input factor, and staff training input factor are compared with the original service quality. The results are shown below.

Figure 6. Sensitivity Analysis Curve: Comprehensive Comparison of Three Parameters

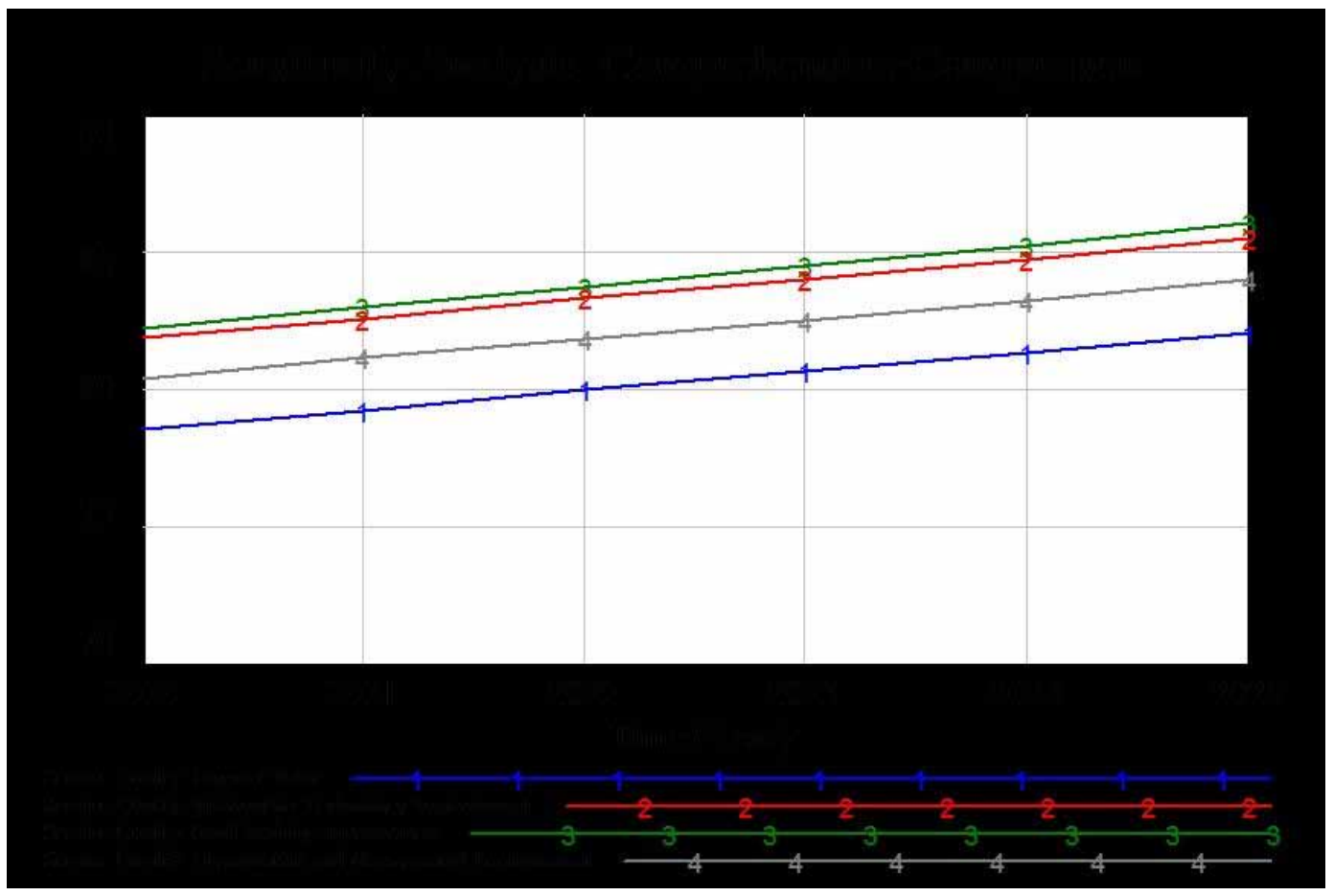

According to the comprehensive comparison curve of the original service quality and the adjusted service quality of the three parameters, the parameter with the highest sensitivity is the staff training input factor. In other words, staff training investment is the work with the highest input-output ratio. The sensitivity of the information technology input factor is relatively close to the staff training input factor. Although the same benefits cannot be obtained as improving staff training when the same resources are invested in information technology, information technology is also an 
important parameter worth investing a lot of resources. The least sensitive of the three parameters is the organization and management input factor, which means that if the same amount of resources are invested in the three aspects of information technology, staff training and the organization and management for improvement, then the benefits of improving the organization and management is the lowest.

\subsection{Policy Experiment}

Sensitivity analysis is the basis of policy experiments. By ranking the sensitivity of the specified parameters in the system dynamics model, the relative weight of each parameter is calculated according to the sensitivity, and the policy plan is designed accordingly. According to the results of sensitivity analysis, it is not difficult to see that in the model, the sensitivity of the three parameters from high to low are: staff training input factor, information technology input factor, organization and management input factor. But it is not enough to just get the order of the sensitivity level, and the relative importance of each parameter needs to be calculated according to the sensitivity. Considering that the sensitivity of each parameter is not completely consistent during 2020-2025, an average value can be used to reflect the average sensitivity of each parameter. Then the average sensitivity of each parameter is normalized to obtain its relative weight. The relative weight of each parameter is shown in the following table.

Table 5. Relative weight of each parameter

\begin{tabular}{|c|c|c|c|}
\hline & $\begin{array}{c}\text { Sensitivity of information } \\
\text { technology input factor }\end{array}$ & $\begin{array}{c}\text { Sensitivity of staff } \\
\text { training input factor }\end{array}$ & $\begin{array}{c}\text { Sensitivity of organization } \\
\text { and management input } \\
\text { factor }\end{array}$ \\
\hline 2020 & 0.426 & 0.463 & 0.236 \\
\hline 2021 & 0.423 & 0.467 & 0.234 \\
\hline 2022 & 0.420 & 0.472 & 0.232 \\
\hline 2023 & 0.417 & 0.477 & 0.230 \\
\hline 2024 & 0.415 & 0.482 & 0.229 \\
\hline 2025 & 0.412 & 0.486 & 0.227 \\
\hline Average value & 0.419 & 0.475 & 0.231 \\
\hline Normalized weight & 0.372 & 0.422 & 0.206 \\
\hline
\end{tabular}

Table 6. Improvement plan of each parameter

\begin{tabular}{|c|c|c|c|}
\hline & $\begin{array}{c}\text { Information technology input } \\
\text { factor }\end{array}$ & $\begin{array}{c}\text { Staff training input } \\
\text { factor }\end{array}$ & $\begin{array}{c}\text { Organization and management } \\
\text { input factor }\end{array}$ \\
\hline Original value & 0.092 & 0.08 & 0.065 \\
\hline $\begin{array}{c}\text { Percentage of } \\
\text { increase }\end{array}$ & $37.2 \%$ & $42.2 \%$ & $20.6 \%$ \\
\hline Improved value & 0.126 & 0.114 & 0.078 \\
\hline
\end{tabular}

The sensitivity of each parameter can reflect its importance to the entire system, that is, the higher the sensitivity, the greater the importance of the parameter. According to the above table, the average value of the sensitivity of the information technology input factor is 0.419 , and the normalized 
weight is 0.372 . The average value of the sensitivity of the staff training input factor is 0.475 , and the normalized weight is 0.422 . The average value of the sensitivity of the organization and management input factor is 0.231 , and the normalized weight is 0.206 .

Assuming that the total resource invested by express delivery companies to improve service quality is $100 \%$, how to allocate these resources scientifically becomes an extremely important issue. In fact, the process of solving this problem is the process of policy experiment. Specifically, according to the weight of each parameter, the parameter value of the model is adjusted accordingly, and the magnitude of each parameter adjustment is determined by its weight, so that the best resource allocation plan can be obtained. In order to more intuitively see the rationality of the resource allocation plan, reference value can be used as the object of comparison. That is, according to the principle of equal distribution of resource, $33.33 \%$ of the resources are invested in each parameter, so that the result when the resources are evenly distributed can be obtained. Finally, the results of equal resource distribution are compared with the results of resource distribution based on the sensitivity analysis to verify the scientific rationality of the policy plan.

Adjust the corresponding parameter value according to the weight of each parameter to obtain the adjusted result. The adjusted result, that is, the improvement plan is shown in the following table.

Table 7. Original value, improved value, and reference value of the prediction results of parcel quantity of the four express delivery companies

\begin{tabular}{|c|c|c|c|c|c|c|c|}
\hline Unit: Billion & \multicolumn{9}{|c|}{} & 2020 & 2021 & 2022 & 2023 & 2024 & 2025 \\
\hline \multirow{4}{*}{$\begin{array}{c}\text { Original value of } \\
\text { prediction }\end{array}$} & STO & 8.646 & 11.167 & 14.440 & 18.689 & 24.206 & 31.37 \\
\cline { 2 - 9 } & ZTO & 17.550 & 24.87 & 32.8 & 42.13 & 52.02 & 63.43 \\
\cline { 2 - 9 } & YTO & 11.439 & 14.987 & 19.640 & 25.744 & 33.752 & 44.255 \\
\hline \multirow{4}{*}{$\begin{array}{c}\text { Improved value of } \\
\text { prediction }\end{array}$} & YD & 15.378 & 21.14 & 29.51 & 40.36 & 53.78 & 68.05 \\
\cline { 2 - 9 } & ZTO & 9.310 & 12.256 & 16.164 & 21.347 & 28.224 & 37.350 \\
\cline { 2 - 9 } & YTO & 12.173 & 16.196 & 21.562 & 28.720 & 38.270 & 51.013 \\
\hline \multirow{3}{*}{$\begin{array}{c}\text { Reference value/ } \\
\text { control value of } \\
\text { prediction }\end{array}$} & YD & 16.538 & 23.186 & 33.007 & 46.002 & 63.036 & 81.565 \\
\cline { 2 - 9 } & ZTO & 9.124 & 11.949 & 15.673 & 20.584 & 27.060 & 35.604 \\
\cline { 2 - 9 } & YTO & 11.972 & 15.861 & 21.027 & 27.886 & 36.995 & 49.094 \\
\cline { 2 - 9 } & YD & 15.921 & 22.197 & 31.440 & 43.645 & 59.045 & 75.876 \\
\hline
\end{tabular}

The express company puts resources into each subsystem, the corresponding parameter values in the subsystem change, and the entire system has also been improved. Therefore, we refer to the adjusted parameter value as the improved parameter value, and the adjusted system operation result as the policy experiment improvement result. According to Table 6, the improved value of the information technology input factor is 0.126 , the improved value of the staff training input factor is 0.114 , and the improved value of the organization and management input factor is 0.078 . In other words, in the system dynamics model, if the new investment is regarded as $100 \%$, then the resource allocation plan corresponding to each subsystem is: $37.2 \%$ of the new investment should be allocated to the logistics information technology subsystem, $42.2 \%$ of the new investment should be allocated 
to the staff professionalism subsystem, and $20.6 \%$ of the new investment should be allocated to the organization and management capability subsystem.

After the improved values of each parameter are obtained, these improved values can be input into the system dynamics model, and the model is run to obtain the improved simulation results. In order to make the improved simulation results comparable, we will compare the results of equal resource distribution with the improved simulation results.

The number of variables in the improved model has not changed compared with the original model. If the values of each variable in the model are used for comparison, it will bring a lot of meaningless and tedious work. Therefore, it is only necessary to select the more important variables in the model for observation and testing to know whether the improvement policy is scientific and reasonable. The parcel quantity is extremely important for any express delivery company. Because the parcel quantity can not only reflect the business status and income of the express company, but also reflect the quality of service. Therefore, the two parameters of parcel quantity and the service quality were used to verify the results of policy experiment.

The prediction results of parcel quantity based on the principle of equal resource distribution and the improved prediction results of parcel quantity based on the sensitivity analysis are as follows.

Although the prediction result of parcel quantity of the four express delivery companies and other relevant data can be drawn from the Table 7. However, it is not intuitive enough to reflect the prediction results. Neither can we directly observe the gap between the improved value and the reference value (control value), nor can we intuitively compare the parcel quantity of the four express delivery companies horizontally. Therefore, it is necessary to use Vensim software to draw the corresponding curve to analyze the results. The relationship between the original value, the improved value and the control value of the parcel quantity prediction results of the four express delivery companies is shown in the figure below.

Figure 7. Policy experiment results of parcel quantity of the four express delivery companies

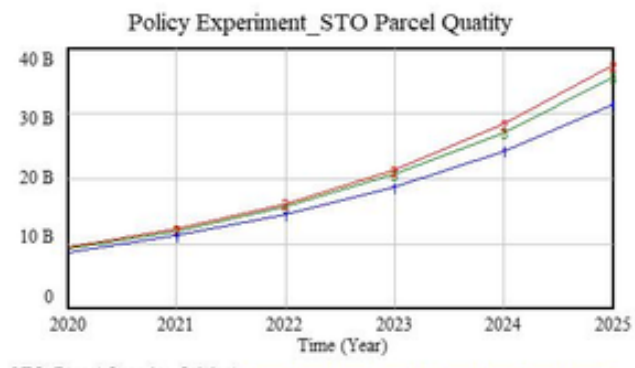

STO_Parcel Quantity_Onginal $+1,+$

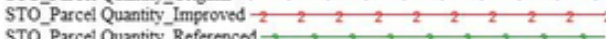
STO_Parcel Quantity Referenced-s

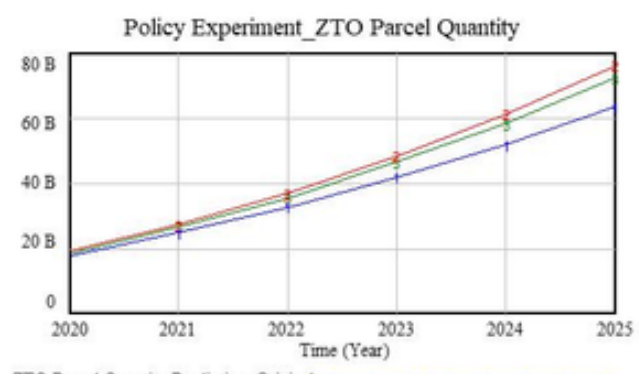

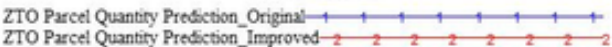
ZTO Parcel Quantity Prediction_Referenced-

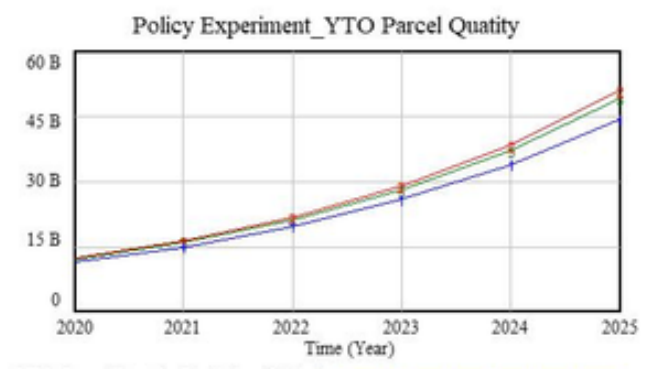
YTO_Parcel Quantity Prediction_Original -1
YTO_Parcel Quantity Prediction_Improved $-2 C_{2}$

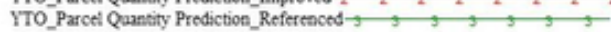

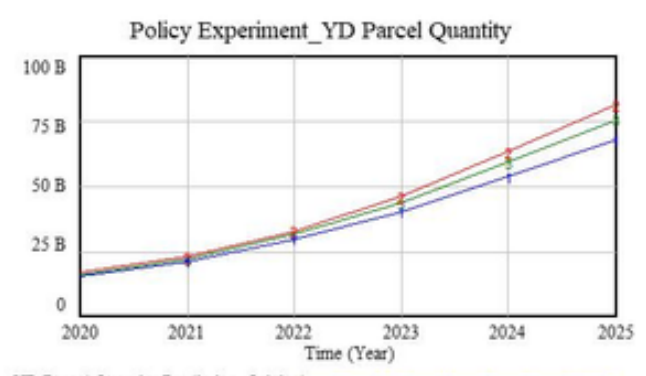

YD Parcel Quancty Prediction_Original
YD Parcel Quantity Prediction_Improwed $C_{2}$,

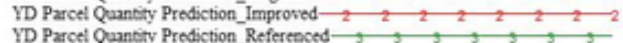


It can be seen from the above figure that, overall, whether the average allocation of resources or the allocation of resources according to the improvement plan can increase the parcel quantity of the four express delivery companies. However, by allocating resources according to the improvement plan, the resources can be used most efficiently. As can be seen from the figure, no matter which express delivery company uses the improved plan to allocate resources, the final result is better than the reference value (control value). Specifically, because the parcel quantity of STO Express and YTO Express is relatively small, the increase of the parcel quantity of these two companies is smaller than that of ZTO Express and Yunda Express. Compared with ZTO Express and Yunda Express, Yunda Express has the most obvious improvement effect. This is mainly because the growth rate of parcel quantity of Yunda is the fastest among the four express delivery companies.

After comparing the improvement results of the parcel quantity of the four express delivery companies, it is necessary to analyze and compare the improvement results of service quality of the four express delivery companies. The service quality prediction results of the four express delivery companies when resources are evenly allocated and when the improvement plan is implemented are as follows.

Table 8. Original value, improved value and reference value of the prediction results of service quality of the four express delivery companies

\begin{tabular}{|c|c|c|c|c|c|c|c|}
\hline & & $\mathbf{2 0 2 0}$ & $\mathbf{2 0 2 1}$ & $\mathbf{2 0 2 2}$ & $\mathbf{2 0 2 3}$ & $\mathbf{2 0 2 4}$ & $\mathbf{2 0 2 5}$ \\
\hline \multirow{4}{*}{$\begin{array}{c}\text { Original value of } \\
\text { prediction }\end{array}$} & STO & 78.55 & 79.23 & 79.92 & 80.62 & 81.33 & 82.05 \\
\cline { 2 - 8 } & ZTO & 76.93 & 77.89 & 78.86 & 79.83 & 80.82 & 81.82 \\
\cline { 2 - 8 } & YTO & 79.46 & 80.30 & 81.19 & 82.13 & 83.12 & 84.14 \\
\hline \multirow{4}{*}{$\begin{array}{c}\text { Improved value of } \\
\text { prediction }\end{array}$} & YD & 74.86 & 75.73 & 76.58 & 77.42 & 78.26 & 79.10 \\
\cline { 2 - 8 } & ZTO & 103.551 & 104.49 & 105.446 & 106.417 & 107.405 & 108.409 \\
\cline { 2 - 8 } & YTO & 100.929 & 102.214 & 103.517 & 104.838 & 106.179 & 107.542 \\
\hline \multirow{3}{*}{$\begin{array}{c}\text { Reference value/ } \\
\text { control value of } \\
\text { prediction }\end{array}$} & YD & 98.2745 & 99.502 & 100.726 & 101.951 & 103.185 & 104.431 \\
\cline { 2 - 8 } & ZTO & 99.9161 & 100.787 & 101.673 & 102.573 & 103.488 & 104.418 \\
\cline { 2 - 8 } & YTO & 100.926 & 102.023 & 103.186 & 104.407 & 105.677 & 106.992 \\
\cline { 2 - 8 } & YD & 89.3762 & 90.4463 & 91.5081 & 92.5676 & 93.6301 & 94.7009 \\
\hline
\end{tabular}

The relationship between the original value, the improved value and the control value of the service quality prediction results of the four express delivery companies is shown in the figure below.

It can be seen from the above figure that, overall, whether the average allocation of resources or the allocation of resources according to the improvement plan can increase the service quality of the four express delivery companies. Specifically, the original prediction result of Yunda's service quality is at the bottom of the four express delivery companies. According to the improvement plan to allocate resources, Yunda Express will get the most benefits. It can be seen from the figure that the gap between the original predicted value of Yunda Express's service quality and the predicted value of the improved plan is the largest among the four express delivery companies. STO Express and ZTO Express use the improved plan to obtain less benefits than Yunda Express, but greater than YTO Express. Contrary to Yunda Express, the difference between the original value of YTO Express's service quality and the predicted value after using the improved plan is the smallest of the 
Figure 8. Policy experiment results of service quality of the four express delivery companies

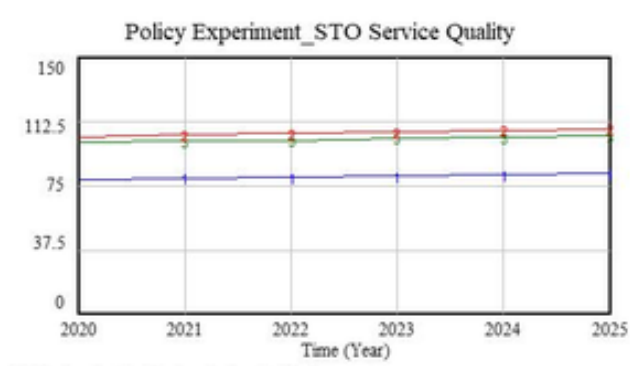

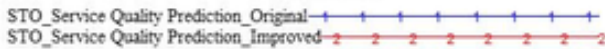

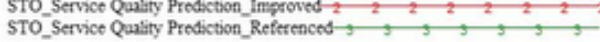

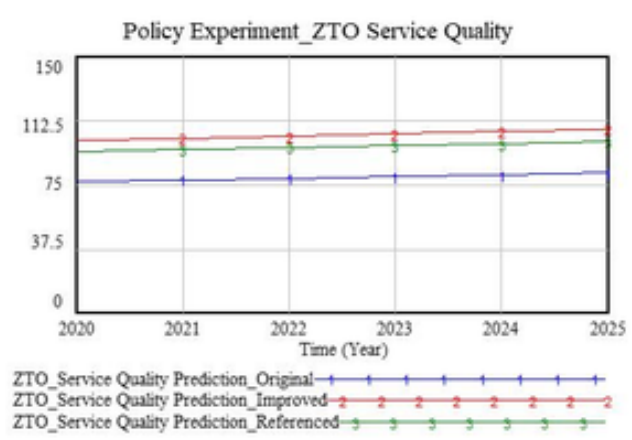

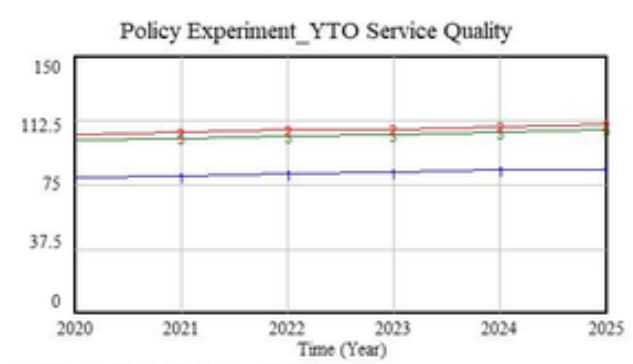

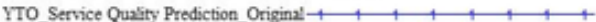
YTO Service Quasty Prediction Improved $-2, l_{2} l_{2} l_{2} l_{2} l_{2} l_{2} l_{2}$

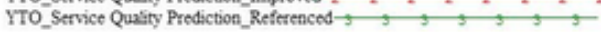

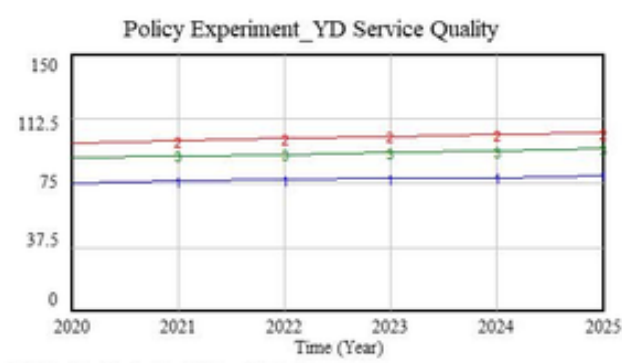

YD_Service Quality Prediction_Original $\rightarrow,,+,,,+$,

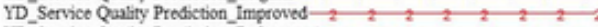
YD_Service Quality Prediction_Referenced.

four express delivery companies. This is mainly because the internal management system, information system and facilities of YTO Express are better than those of the other three express companies.

\section{CONCLUSION}

According to the results of simulation prediction, with the development of China's e-commerce and the continuous improvement of people' consumption levels, the parcel quantity, business outlets and service quality of the four express delivery companies have shown a continuous growth trend. Specifically, the improvement of service quality is the result of the sound development of the private express delivery industry. The continuous growth of the parcel quantity reveals the huge growth potential of the express delivery industry, that is, express delivery is a sunrise industry that is worth investing resources and giving policy support. The continuous growth of the number of business outlets not only means the expansion of the scale of express delivery companies, but also indicates that the emphasis of express delivery companies on customer experience is gradually increasing.

In addition, the result of sensitivity analysis shows that the parameter with the highest sensitivity is the staff training input factor. In other words, staff training investment is the work with the highest inputoutput ratio. Therefore, the personnel management should be adjusted based on the results of the sensitivity analysis, and the focus should be on staff training. For instance, express delivery companies can improve the overall quality of staffs by raising the threshold of recruitment, thereby reducing the difficulty of training, and also can increase the investment in staff training by regularly holding skills training and expert lectures.

The results of the policy experiment show that if the new investment is regarded as $100 \%$, then the resource allocation plan corresponding to each subsystem is: $37.2 \%$ of the new investment should be allocated to the logistics information technology subsystem, $42.2 \%$ of the new investment should be allocated to the staff professionalism subsystem, and $20.6 \%$ of the new investment should be allocated to 
the organization and management capability subsystem. The results of the policy experiment provide a reference for the resource allocation decision-making of China's private express companies, and enable the leaders of the companies to clarify the key areas of resource input when making decisions.

\section{LIMITATIONS AND FUTURE DIRECTIONS}

\subsection{Limitations}

The system dynamics method is used to systematically analyze and study the service quality of China's private express delivery. The results can help the operation and management of private express delivery companies and the decision-making of relevant government departments, but there are also some shortcomings, including the scope of research, and absolute accuracy of data.

The scope of research is mainly concentrated in the mainland of China. Because China's Hong Kong, Macau and other regions have adopted the "one country, two systems" policy, the market policies and the operation of express delivery companies in these regions are quite different from those in mainland China. In addition, a small number of China's private express delivery companies, such as ZTO Express, STO Express and YTO Express, have already launched international express delivery service. However, due to the availability of data and the accuracy of the research scope, this article did not consider and study the international business of private express delivery.

In the data collection process of the empirical analysis, the actual values of the three indexes of the business income, the parcel quantity and the number of existing outlets of the four express delivery companies can be obtained through their respective annual reports. However, the value of the two indexes of order information update timeliness and timely delivery rate cannot be obtained through the annual report, because express companies will keep the relevant data related to internal operation efficiency strictly confidential. In this case, the two indexes of order information update timeliness and timely delivery rate cannot be directly obtained, and some relevant data can only be calculated and speculated through the package tracking number of each express company.

\subsection{Future Directions}

The research result has certain limitations in terms of research scope and absolute data accuracy. In the future research work, we can continue to improve from the following aspects, so as to effectively promote the improvement of the service quality of China's private express delivery.

It is possible to broaden the channels to collect data from express delivery companies in Hong Kong, Macau, and Taiwan to construct an optimized system dynamics model. In addition, a small number of China's private express delivery companies have already launched international express delivery service, so relevant factors of international express delivery service can be taken into account in the process of structure analysis and modeling, so that the finally constructed model can reflect the operating conditions of various express delivery enterprises.

Future research work can solve the problem of data availability with the help of professional research institutions and the decision consulting companies. That is to say, the data that cannot be directly obtained can be accessed by purchasing research reports or subscribing key data. Because although the business information of the enterprise is not disclosed to social individuals, professional research institutions can obtain many first-hand data through government departments and other channels.

Conflicts of Interest: The author declares no conflict of interest. The funders had no role in the design of the study; in the collection, analyses, or interpretation of data; in the writing of the manuscript, or in the decision to publish the results.

\section{FUNDING AGENCY}

Open Access Funding for this article has been covered by the authors of this manuscript. 


\section{REFERENCES}

Abdel-Hamid, T. K. (1989). The dynamics of software project staffing: A system dynamics based simulation approach. IEEE Transactions on Software Engineering, 15(2), 109-119. doi:10.1109/32.21738

Anderson, R. D., Crum, M. R., \& Jerman, R. E. (1996). Relationship of work improvement Program experience and logistics quality management factors. Transportation Journal, 9(4), 71.

Angerhofer, B. J., \& Angelides, M. C. (2000). System dynamics modelling in supply chain management: research review. Paper presented at the Simulation Conference. doi:10.1109/WSC.2000.899737

China Express Development Index Report. (2020). Retrieved from http://www.spb.gov.cn/xw/dtxx_15079/202003/ t20200327_2068989.html

China State Council. (2015). Some Opinions on Promoting the Development of the Express Delivery Industry. Retrieved from http://www.gov.cn/zhengce/content/2015-10/26/content_10256.htm

Dang, Y., \& Wagn, H. R. (2016). Fuzzy Evaluation of EMS Service Quality Based on SERVQUAL and LSQ Model. Commercial Research, 2, 170-175.

De Giovanni, L., Gastaldon, N., \& Sottovia, F. A. (2019). two-level local search heuristic for pickup and delivery problems in express freight trucking. Networks, 74(4), 333-350. doi:10.1002/net.21917

Dean, J., \& Page, J. (2011). Trouble on the China Express. The Wall Street Journal, 30.

Forrester, J. W. (1958). Industrial dynamics: A major for decision makers. Harvard Business Review, 36(4), 37-66.

Forrester, J. W. (1994). System dynamics, systems thinking, and soft OR. System Dynamics Review, 10(2), 245-256. doi:10.1002/sdr.4260100211

Huang, Z., \& Liu, D. (2005). China's Logistics System for Agricultural Products: Their Development and Institutional Aspects. Problem of Agricultural Economy, 4, 9.

Kafle, N., Zou, B., \& Lin, J. (2017). Design and modeling of a crowdsource-enabled system for urban parcel relay and delivery. Transportation Research Part B: Methodological, 99, 62-82. doi:10.1016/j.trb.2016.12.022

Kao, S.-P., Chen, Y.-C., Wu, C.-M., \& Yang, H.-C. (2005). Using System Dynamics to Simulate the Urban Area Development and Water Resources. Journal of Ecotechnology, 1(2).

Kim, T. Y., Dekker, R., \& Heij, C. (2017). Cross-border electronic commerce: Distance effects and express delivery in European Union markets. International Journal of Electronic Commerce, 21(2), 184-218. doi:10. 1080/10864415.2016.1234283

Li, X. D., \& Xie, R. Q. (2016). Research on the construction of the long-term service quality guarantee system of the electronic business express enterprise. Journal of Tianjin College of Commerce, 4(1), 36-40.

Lin, W. T. (2016). Crowdsourcing Logistics Service Quality Evaluation Based on System Dynamics (Master). Beijing Jiaotong University.

Luna-Reyes, L. F., \& Andersen, D. L. (2003). Collecting and analyzing qualitative data for system dynamics: Methods and models. System Dynamics Review, 19(4), 271-296. doi:10.1002/sdr.280

Mentzer, J. T., Flint, J. H., \& Hult, G. T. M. (2001). Logistics service quality as a segment customized process. Journal of Marketing, 4(4), 140-145. doi:10.1509/jmkg.65.4.82.18390

Mentzer, J. T., Gomes, R., \& Krapfel, R. E. (1989). Physical distribution service: A fundamental marketing concept. Journal of the Academy of Marketing Science, 17(1), 53-62. doi:10.1007/BF02726354

Olbert, H., Protopappa-Sieke, M., \& Thonemann, U. W. (2016). Analyzing the effect of express orders on supply chain costs and delivery times. Production and Operations Management, 25(12), 2035-2050. doi:10.1111/ poms. 12588

Pan, G., \& Jian, T. (2011). A Study on the Sustainable Development of Private Express Companies in Online Shopping Environment. Value Engineering, 11, 11. 
Perreault, W. D., \& Russ, F. A. (1976). Physical distribution service in industrial purchase decisions. Journal of Marketing, 40(2), 3-10.

Rabinovich, E., \& Bailey, J. P. (2004). Physical distribution service quality in Internet retailing: Service pricing, transaction attributes, and firm attributes. Journal of Operations Management, 21(6), 651-672. doi:10.1016/j. jom.2003.11.004

Sterman, J. D. (2001). System dynamics modeling: Tools for learning in a complex world. California Management Review, 43(4), 8-25. doi:10.2307/41166098

Vakulenko, Y., Hellström, D., \& Hjort, K. (2018). What's in the parcel locker? Exploring customer value in e-commerce last mile delivery. Journal of Business Research, 88, 421-427. doi:10.1016/j.jbusres.2017.11.033

Wu, Y. F. (2009). Analysis of the Competition of the Express Market in China. Social Science of Beijing, $2,2$.

Zenezini, G., Lagorio, A., Pinto, R., De Marco, A., \& Golini, R. (2018). The collection-and-delivery points implementation process from the courier, express and parcel operator's perspective. IFAC-PapersOnLine, 51(11), 594-599. doi:10.1016/j.ifacol.2018.08.383

Zhao, Y. Q., \& Zhuang, J. F. (2011). The Problem and Development of Private Express Delivery Companies Based on E-Commerce. Logistics Sci-Tech, 8, 26.

Zhu, M. H., \& Miao, S. T. (2011). An empirical study on service quality evaluation of Chinese express industry based on SERVQUAL. Science and Technology Management Research, 8, 38-45.

Zhuang, D. L., \& Li, J. (2015). Research on Evaluation of Express Enterprise Service Quality Based on CZIPA Method. Journal of Beijing Technology and Business University, 2, 48-55. 